\title{
SOBRE Mülberger, Annette (ed.). Los límites de la ciencia: espiritismo, hipnotismo y el estudio de los fenómenos paranormales (1850-1930)
}

Hugo Leonardo Rocha Silva da Rosa; Marcus Vinicius do Amaral Gama Santos; Leticia Gomes Canuto; André Elias Morelli Ribeiro; Mateus dos Santos Martins; Rafael de Souza Lima; Yuri Pereira Antunes Vieira; Arthur Arruda Leal Ferreira; Victoria Fattore

Universidade Federal do Rio de Janeiro

\section{Resenha de:}

MÜLBERGER, Annette (ed.). Los límites de la ciencia: espiritismo, hipnotismo y el estudio de los fenómenos paranormales (1850-1930). Madrid: Consejo Superior de Investigaciones Científicas, 2016.

DOI: 10.12957/mnemosine.2020.57676

O livro Los límites de la ciencia - Espiritismo, Hipnotismo y el Estudio de los Fenómenos Paranormales (1850-1930) é uma obra coletiva organizada pela historiadora da ciência e professora da Universitat Autònoma de Barcelona, Annette Mülberger. Publicado em 2016 pelo Consejo Superior de Investigaciones Científicas, na Espanha, o livro conta com a autoria de outros cinco pesquisadores que trazem ricas narrativas e reflexões sobre a história, em contexto europeu, do espiritismo, do hipnotismo e de outros fenômenos classificados na época como paranormais.

A introdução do livro, escrita por Mülberger, inicia com um aviso: esta obra não tem por objetivo contribuir com novos argumentos para a secular polêmica sobre a veracidade dos fenômenos paranormais - seja a favor ou contra quem a questiona. Segundo a autora, o propósito da obra é contribuir para a compreensão de fenômenos e crenças que foram reconhecidos como científicos e/ou racionais por alguns grupos de indivíduos entre a segunda metade do século XIX e as primeiras décadas do século XX.

O livro é dividido em três partes nas quais oito capítulos foram distribuídos de acordo com o seu foco de pesquisa: apresentação geral e histórica dos temas abordados, narrativas historicamente localizadas na Espanha e estudos que abordam a paranormalidade em outros países da Europa.

No primeiro capítulo, Los Inicios del Movimiento Espiritista en el Siglo XIX, Mülberger começa com o evento já consagrado como marco inicial do espiritismo moderno - os golpes de Hydesville, nos EUA, protagonizados pelas irmãs Fox. Seriam sons de batidas na estrutura da casa e nos móveis, mensagens cifradas de espíritos que assombravam a casa onde a família Fox 
vivia. Mülberger indica que ali se iniciou o renascimento ocultista nos EUA, mas que rapidamente se espalhou pelo resto das Américas, indo em direção à Europa. A opção da autora a coloca em uma perspectiva histórica específica ao reconhecer nesses acontecimentos a refundação do movimento espírita, considerando a diferença que faz entre esse espiritismo e aquele praticado por seguidores de Swedenborg, místico e cientista sueco que já possuía igreja e adeptos nos EUA. O caminho da versão do espiritismo iniciada pelas irmãs Fox passa a ser, então, o fio condutor não só do capítulo, mas de grande parte do livro. O panorama continua com outros médiuns e figuras famosas, como Daniel Home, Robert Owen e Alain Kardec auge do espiritismo na França e com muitos adeptos no Brasil. Outras versões do espiritismo aparecem apenas eventualmente, pois fogem do núcleo de discussão do livro.

O segundo capítulo, El Espiritismo Llega a España: El Choque con la Iglesia y el Primer Congreso Internacional, mostra ao leitor alguns aspectos importantes do movimento espírita na Espanha. O primeiro deles são os conflitos dos espíritas com a Igreja Católica, cujo poder e influência provocou queimas de livros e perseguições às doutrinas espíritas. De modo interessante, a autora assinala como esses conflitos tiveram um efeito contrário ao esperado, isto é, despertaram na população um interesse pelo proibido e um sentimento anticatólico. Apesar da face mais violenta, as tensões também produziram ricos debates na imprensa periódica. Em segundo lugar, a autora também mostra que, apesar de o espiritismo espanhol ter tido personalidades muito importantes (como a médium Amália Domingo), fundamentais para compreender sua expansão, se trata de um movimento muito plural. Ainda que o legado de Kardec tenha oferecido uma orientação, o espiritismo se disseminou em muitas práticas e se capilarizou por todas as classes sociais. Um terceiro eixo muito importante é o exame de seu crescimento e das pretensões de suas lideranças. O espiritismo não se limitou aos estudos psíquicos ou às exibições públicas, pelo contrário: como mostra a autora por meio das atas do congresso internacional, pretendeu ser um projeto de reforma política e social, buscando traçar diretrizes diversas, entre as quais se situam, por exemplo, aquelas voltadas para a educação.

Já o terceiro capítulo, intitulado La Investigación de Lo Paranormal, trata da preocupação com a demonstração científica dos fenômenos espíritas. Essas investigações empíricas, para as quais os esforços dos praticantes do kardecismo espanhol foram direcionados, seriam associados, segundo Mülberger, ao âmbito que hoje conhecemos como “parapsicologia”. Objetivamente, a análise realizada no capítulo tenta dar conta de responder a questionamentos como "Qual foi a relação entre espiritismo e ciência?", realizando, com esse 
intento, uma revisão histórica que abarca o período de 80 anos contido no intervalo de 1850 a 1930. A autora, no que diz respeito à metodologia, opta por começar analisando as iniciativas internacionais (Grã-Bretanha, França e Alemanha) que precederam e influenciaram as empreitadas parapsicológicas espanholas. Um dos exemplos usados para ilustrar essas tentativas de investigações científicas de fenômenos paranormais diz respeito aos experimentos realizados por médicos para comprovar os movimentos giratórios de mesas e outros objetos. Dessa forma, partindo desses exemplos, Mülberger ilustra como o interesse de alguns cientistas, a partir da década de 1850, voltou-se para os estudos acerca dos fenômenos paranormais. A autora também demonstra, ao longo do capítulo, que, embora alguns cientistas tenham esforçadamente procurado qualificar esses fenômenos como "falsos" e fundamentados puramente na superstição de seu público, a expansão do espiritismo e do número de adeptos dessas experiências mediúnicas não foi impedida e, inclusive, levou consigo alguns cientistas que se aproximaram e até mesmo apoiaram essas práticas.

O quarto capítulo, 'Ahuyentar los Espíritus': El Estudio Cientifico de la Mediumnidad, escrito por Andrea Graus, trata da mediunidade como objeto de investigação científica no contexto europeu, com destaque para a Espanha. A autora defende que, no final do século XIX, houve uma paulatina apropriação da mediunidade pelo âmbito científico, gerando assim uma nova concepção do médium como produtor do fenômeno mediúnico. A suposta comunicação com os espíritos se converteu em objeto de estudo dos novos campos de investigações psíquicas, da metapsíquica e, mais tarde, da parapsicologia. Graus elenca alguns dos primeiros autores da investigação científica dos fenômenos relacionados ao espiritismo na Espanha e expõe três formas como se pensou a mediunidade a partir das investigações psíquicas, campo que se distingue da doutrina espírita, uma vez que esta atribui ao médium o papel de intermediário passivo da comunicação dos espíritos. Ela foi pensada pelos cientistas como um fenômeno natural, como uma faculdade latente da raça humana e como um objeto de estudo científico próximo ao sonambulismo, mas não equiparável ao mesmo. Estas formas eram complementares, não excludentes entre si e constituíam maneiras de entender o médium fora do escopo do espiritismo, descartando, desta forma, a hipótese da atividade dos espíritos. Além disso, a autora mostra que o debate científico sobre a mediunidade também teve impacto na esfera pública, por exemplo: nas iniciativas dos cientistas para incluir a participação dos cidadãos, através de enquetes para reunir testemunhos sobre os fenômenos espíritas, e pela oferta de desafios e prêmios, difundidos pela imprensa, com o intuito de provar ou desmentir 
um fenômeno. Por outro lado, dentro do movimento espírita também houve a oferta de prêmios aos incrédulos para que demonstrassem que os fenômenos não decorriam da intervenção dos espíritos. $\mathrm{O}$ artigo mostra, nesse debate, o modo como a ciência se apropriou da mediunidade como objeto de estudo, havendo nisso ambições distintas das propostas pelo espiritismo, como as de revelação dos prodígios de que eram capazes o homem e o avanço da psicologia. Da parte dos cientistas, por vezes houve a tentativa de imposição de condições de controle experimental; todavia, os espíritas também exigiam certas condições para a realização de suas experiências mediúnicas, quando desafiavam os cientistas a refutar sua doutrina. Desta forma, percebe-se a constituição de um interessante campo de disputa da mediunidade, que se tornou o foco de distintos interesses e implicou a construção de diferentes saberes.

Ángel González de Pablo escreveu o quinto capítulo, de título Consolidar, Colonizar, Excluir: Estrategias de legitimación de la hipnosis médica. Primeiramente, o autor contextualiza historicamente a hipnose, para logo em seguida discorrer sobre três estratégias pelas quais teria ocorrido a legitimação da hipnose na Espanha entre a década de 1880 e 1920 . Aqui, utiliza-se do conceito de Boundary Work de Thomas F. Gieryn para realizar uma tarefa de delimitação deste processo, tônica que define a narrativa e que expõe suas teses, percorrendo diferentes articulações e apropriações feitas destas ideias e práticas. A Consolidación, primeira estratégia abordada, consistiu na busca por uma legitimidade científica dentro da área médica, por exemplo: pelo abandono de explicações como a do fluido magnético mesmeriano; pela utilização da psicobiologia, ao falar de hemisférios cerebrais e estados de consciência; e, na ciência experimental, pelo desenvolvimento de uma série de instrumentos e aparatos hipnóticos que auxiliariam suas aplicações terapêuticas. A Colonización, segunda estratégia, consistiu na legitimação da hipnose através da expansão de seu território para além da medicina, adentrando o direito e a pedagogia, atentando-se menos para sua validação teórica e mais para suas implicações práticas. No campo judicial, foi destacado seu suposto uso para fins criminosos, aproveitando-se do estado de sugestibilidade dos hipnotizados para "convencê-los" a cometer crimes. Já no pedagógico, era utilizada para a correção de problemas morais de jovens e, embora não tenha ganho muita relevância dentro das escolas, foi abordado em muitas obras do período, incluindo as literárias. E, por último, a Exclusión, a menos “inteligível” das estratégias, que consistiu tanto na Cuarentena da hipnose, quanto em seu uso para a Patologización de certos fenômenos. A quarentena se pautou no não-diálogo da hipnose com outros campos, consistindo em uma tentativa de sua "purificação", utilizando-se de argumentos como a existência de uma 
“impureza científica", como teria ocorrido nos estudos parapsicológicos. Também inserida nesta estratégia estaria a utilização dos fenômenos hipnóticos para a patologização de experiências espíritas, alertando para o uso indevido da hipnose por aqueles que não fossem hipnólogos.

Assim como os dois últimos capítulos, o sexto capítulo, La prática de la Metapsíquica: Un Marqués Investigando la Clarividencia, possui uma tomada mais autoral: aqui, Mònica Balltondre busca delinear as práticas da metapsíquica por meio das pesquisas e atividades do Marquês de Santa Cara sobre clarividência. Esse talvez seja um dos capítulos mais originais, pois é o único texto em que um personagem é considerado em uma abordagem ao mesmo tempo extensa nas suas conexões e com maior intensidade no detalhamento das atividades. No entanto, mais do que um relato biográfico, o que o capítulo oferece é uma conexão das práticas metapsíquicas, através da história do marquês, com vários domínios: os saberes psi, a física, o espiritismo, a literatura, a história, os complexos tecnológicos, as contraposições da igreja católica, as posições políticas carlistas, fascistas e com o próprio franquismo, entre outras esferas. Assim, temos um complexo de saberes que se deslocam em rede, conectando "certos valores religiosos como infinitude, eternidade e mistérios, a novos descobrimentos e teorias científicas da época como o inconsciente, a relatividade ou as teorias sobre raios e a transmissão de ondas" (BALLTONDRE, 2016: 195). Um dos destaques é a descrição densa dos experimentos e demonstrações do marquês, especialmente com seu filho primogênito, Joaquín Argamasilla, considerado clarividente. Para trabalhar o tema, ele se valia de médiuns, objetos psicométricos e hipnose (na versão mesmeriana) como forma controlada de abordagem, gerando o que o Marquês denominava clarividência experimental. Outro destaque na abordagem do capítulo é o uso do conceito de inconsciente como central na explicação das atividades psíquicas (incluindo pitadas místicas), muito antes de seu fechamento pelas abordagens psicanalíticas. Igualmente, houve uma clara apropriação de imagens de dispositivos técnicos (como o telégrafo e o cinematógrafo) e científicos (o éter, o conceito de ondas na física e, até mesmo, a teoria da relatividade). Aqui fica clara a vinculação da metapsíquica como “ciência síntese' que iria revolucionar tanto as ciências humanas como as físicas" (BALLTONDRE, 2016: 221), em que elas iriam revelar uma natureza espiritual profunda, numa concepção panpsiquista. Foi este agenciamento de componentes extremamente singulares que a metapsíquica assinada pelo Marquês de Santa Cara pôde sustentar até o seu falecimento em 1940. 
O sétimo capítulo, Videncias en Europa Ocidental, de Nicole Edelman, talvez seja o que menos apresenta novidades dentre os capítulos autorais. Aqui é apresentada uma visão geral quanto à influência dos fenômenos ocultos e psíquicos na cultura geral da Europa no início do século XX. As duas primeiras seções, sobre o interesse geral pelo ocultismo e a influência do estudo dos fenômenos psíquicos na medicina, fornecem uma ampla gama de exemplos de artistas e autores influentes cujo trabalho foi influenciado por tais fenômenos. A escolha de exemplos é abrangente, envolvendo pessoas que tiveram forte influência na academia e na cultura de sua época (como Freud e Jung), embora a autora reitere com frequência que o amplo interesse pelo ocultismo se deveu às incertezas do período entre guerras, sem apresentar qualquer suporte para esta tese. A última seção trata principalmente da astrologia, tanto em nível acadêmico quanto popular. A maioria dos autores e trabalhos que são discutidos nessa seção são mais obscuros e a discussão das publicações mencionadas na última metade poderia ser mais sucinta, já que algumas delas se tornam bastante repetitivas e não acrescentam muito aos seus argumentos principais. No entanto, o capítulo é bem-sucedido em seu objetivo de mostrar o quanto o interesse pelos fenômenos psíquicos permeou a sociedade europeia em todos os níveis.

No oitavo e último capítulo, intitulado Espiritismo Ruso: Ciencia y Conocimiento Público, Michael D. Gordin investiga um episódio-chave para a história do Espiritismo na Rússia: a criação, pela Sociedade Russa de Física, de uma comissão científica liderada pelo químico Dmitri Ivanovich Mendeléyev - atualmente conhecido pela formulação da tabela periódica dos elementos químicos - para a investigação da veracidade dos fenômenos mediúnicos e que, em última instância, buscava erradicar o espiritismo. Tal episódio, segundo o autor, seria uma resposta à querela social da época que envolvia a delimitação dos que poderiam ou não determinar legitimamente as leis que governam a natureza. Os espiritistas, por um lado, admitiam a existência de leis naturais, pois consideravam os fenômenos que investigavam como consequentes delas; por outro lado, questionavam a exclusividade reivindicada e desfrutada por Mendeléyev e seus colegas cientistas para delas tratar. De forma mais ampla, essa luta pela legitimidade estaria inserida em uma conjuntura histórica muito específica: após a Reforma Emancipadora Russa de 1861, a nobreza vinha perdendo grande parte de seus privilégios; e, para tentar retomar parte de sua condição social, se valeu do espiritismo - enquanto discurso sobre as leis naturais -, visando se apropriar de parte da autoridade cultural devotada na época à ciência, fato que desencadeou uma disputa com os 
cientistas naturais. O capítulo trata, portanto, de questões referentes aos limites da ciência e às guerras travadas visando retraçar estes limites: Gordin expõe as estratégias ofensivas e defensivas das quais cada uma das partes - partidários e opositores do espiritismo - se valeu para vencer a disputa; e também evidencia que, em última instância, não se trata da questão de se os espiritistas são ou não falsários, se eles acreditam em coisas que existem ou que não existem, mas sim da questão relativa a quem deve ser escutado e quem deve ser ignorado quando o que está em questão são as leis da natureza.

Annette Mülberger retorna para apresentar-nos o epílogo do livro, no qual recapitula e analisa algumas das principais questões e teses apresentadas ao longo da obra. O foco do epílogo é discorrer sobre a relação entre as práticas paranormais, hipnóticas e espíritas e a ciência da época estudada. Mülberger relembra que a maior parte dos cientistas se manteve distante do estudo dessas práticas. Outros se empenharam vigorosamente para provar que não passavam de superstições incompatíveis com a ciência. Poucos foram os que desafiaram os julgamentos de seus pares e iniciaram pesquisas de forma franca e tolerante.

Diversos outros prismas de análise sobre os assuntos estudados são apresentados ao longo do livro. É especialmente interessante o modo como os autores demonstram os possíveis vínculos que essas práticas possuíam com questões sociais, ideológicas e políticas da época, dentro e fora das divisas espanholas. As temáticas tratadas de forma rica e detalhada fazem com que o livro seja uma leitura proveitosa tanto para um leigo curioso sobre o assunto quanto para um pesquisador em busca de uma rica referência para a sua pesquisa. 